\title{
Post-discharge evaluation of medication adherence and knowledge of hypertension among hypertensive stroke patients in northwestern China
}

This article was published in the following Dove Press journal:

Patient Preference and Adherence

Number of times this article has been viewed

\author{
Jingjing Pan' \\ Tao Lei $^{2}$ \\ Bin $\mathrm{Hu}^{\prime}$ \\ Qiongge $\mathrm{Li}^{\prime}$ \\ 'Department of Pharmacy, \\ 'Department of Neurology, \\ Xi'an Fourth Hospital, Xi'an, \\ People's Republic of China
}

Correspondence: Jingjing Pan Department of Pharmacy, Xi'an Fourth Hospital, 21 JieFang Road, 710004 Xi'an, People's Republic of China Tel +8602987480635 ext 029 Email pansyjing1984@126.com
Objectives: The aims of this study were to assess the knowledge of hypertension (HTN) and investigate risk factors associated with medication adherence among hypertensive stroke patients after discharge in northwestern China.

Patients and methods: A cross-sectional study involving 440 Chinese hypertensive stroke patients was conducted in a tertiary hospital in Xi' an, China. Data were collected by telephone interviews and patients' medical records.

Results: It was found that $35.23 \%$ of patients were compliant with their antihypertensive drug treatments, and $42.95 \%, 52.27 \%$ and $4.77 \%$ of patients had poor, moderate and adequate knowledge of HTN, respectively. Gender, blood pressure (BP) categories, BP monitoring and HTN knowledge were independently associated with antihypertensive medication adherence.

Conclusion: The medication adherence among hypertensive stroke patients in northwestern China was poor. Knowledge of HTN was suboptimal. More attention and effective strategies should be designed to the factors affecting medication adherence. As knowledge positively affects medication adherence, clinical pharmacists should play an important role in patients' medication education.

Keywords: medication adherence, knowledge, hypertension, stroke, clinical pharmacist, China

\section{Introduction}

Stroke is a common complication of hypertension (HTN). There is overwhelming evidence to indicate that poorly controlled HTN increases the risk of stroke. The elevated blood pressure (BP) increases the incidence of both ischemic stroke and hemorrhagic stroke. ${ }^{1,2}$ About $51 \%$ of stroke deaths of the world attributes to high systolic BP. ${ }^{3}$

Numerous studies have demonstrated that antihypertensive drug therapy reduces the incidence of strokes in individuals of both genders, all ages and those with systolic and diastolic HTN or isolated systolic HTN. ${ }^{4}$ However, the control rate of HTN remains low. In the USA, an estimated $53.5 \%$ of hypertensive patients did not have their BP under control. ${ }^{5}$ A study involved a total of 25,936 subjects from 1999 to 2009 in China showed that the proportion of people who had controlled their HTN was only $30 \%{ }^{6}$ Another study showed that the average control rate was only $17.2 \%$ for the Chinese hypertensive population treated with antihypertensive drugs. ${ }^{7}$

The effectiveness of antihypertensive drugs must be achieved by optimal medication adherence. Medication adherence is defined as the process by which patients take their medication as agreed upon with their prescriber. ${ }^{8}$ Optimal antihypertensive drug adherence has significantly positive association with BP control. ${ }^{9-11}$ The influence of 
nonadherence to antihypertensive drugs is the most important reason for uncontrolled BP. Almost three-quarters of the hypertensive patients could not achieve the optimal BP control because of drug nonadherence. ${ }^{12}$ A recently published review identified that $45.2 \%$ of the hypertensive patients were nonadherent to antihypertensive medications; the rate reached up to $83.7 \%$ in uncontrolled hypertensive patients. The study also showed that the percentage of nonadherence levels was higher in Asia (43.5\%) and Africa (62.5\%) than in Europe (36.6\%) and America (36.6\%). ${ }^{13}$

Barriers to medication adherence consist of multiple factors including patient-related factors, social/economic-related factors, condition-related factors, therapy-related factors and health care team-related factors. ${ }^{14,15}$ Some of the barriers are under the patient's control such as patient's knowledge about the HTN and hypertensive medicines. A better understanding of adherence barriers is vital to determine strategies to improve medication adherence. ${ }^{16}$

In this study, we focused on the medication adherence and knowledge of HTN among hypertensive stroke patients after their discharge within about 2 years in northwestern China. Although there are several studies focused on medication adherence, still marked geographical differences exist in the hypertensive medication adherence. A recently reported meta-analysis showed that the majority of factors affecting nonadherence to antihypertensive medication were social and economic factors in low- and middle-income countries. ${ }^{17}$ China is a developing country, and the economic development of different regions is unbalanced. The economy in the eastern district is prosperous, while the western region is very far behind. Adherence to medication for northwestern patients has long been given minor attention. There is a scarcity of studies assessing antihypertensive medication adherence and knowledge of HTN among patients in northwestern China, where it is an undeveloped region in China with the culture and economic development different from other developed regions.

The study aimed to assess whether the patients continued their antihypertensive drug treatment after discharge and evaluate the factors influencing the drug adherence. In addition, the level of knowledge of HTN has also been investigated. The findings of the study can provide more comprehensive information for health care providers and health care policy makers with targets to improve drug adherence.

\section{Patients and methods}

A cross-sectional study was carried out by trained clinical pharmacists in Xi'an Fourth Hospital of Shaanxi province, where it locates in northwestern China. The hospital is a tertiary hospital with a bed capacity of 800 beds and has a 45-bed neurology unit. The study was approved by the ethics committee of Xi'an Fourth Hospital. Verbal consent from all participants was obtained.

A total of 564 patients were randomly selected from the database of the hospital. These patients were hospitalized in the neurology unit during the period from January 1, 2013 to December 31, 2014.

The minimum sample size was calculated using the following formula:

$$
\mathrm{S}=\mathrm{z}^{2} \frac{[\mathrm{p}(1-\mathrm{p})]}{\mathrm{d}^{2}}
$$

where $\mathrm{s}$ is the minimum sample size, $\mathrm{z}$ is the standard normal variate, $p$ is an estimate of medication adherence of the patients in the study and $d$ is the sample error to be tolerated. ${ }^{18}$ Predicted medication adherence of the patients was $50 \%$, which referred to former related papers concerning Chinese people. ${ }^{19,20}$

As a minimum sample size of 384 patients was required, 440 hypertensive stroke patients were recruited finally as shown in Figure 1. The inclusion criteria were as follows: hypertensive patients 1 ) aged at least 18 years and who agreed to attend the study, 2) who took antihypertensive drug therapy in the duration of being in hospital, 3) who were diagnosed with stroke by neurological physician, 4) who had a telephone contact records in their medical charts. The exclusion criteria were as follows: 1) patients with brain tumor or traumatic

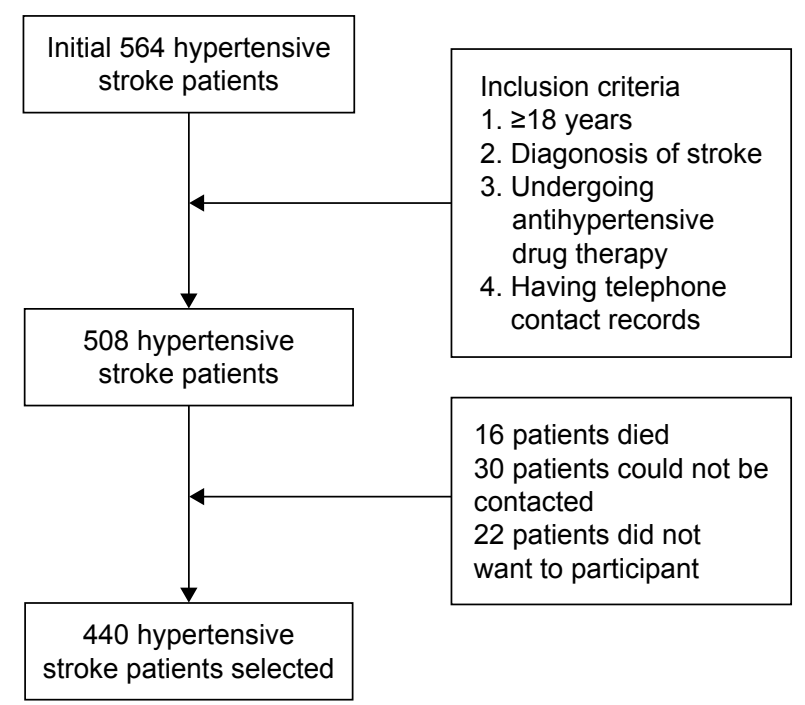

Figure I Flowchart of inclusion of hypertensive stroke patients. 
hemorrhagic stroke, 2) patients who cannot communicate due to physical or mental problems, 3) pregnant women.

The patients' data referring to sociodemographic factors and part of clinical data including duration of HTN and BP categories were collected by reviewing the electronic medical records. The other clinical data such as hypertensive stroke patients' drug treatment, the experience of side effects, BP monitoring, drug adherence and knowledge of HTN were collected by clinical pharmacists through telephone survey from January to May 2015. The follow-up of health data by telephone is a method that has been used frequently before. ${ }^{21}$

HTN medication adherence was measured using Chinese version of Morisky, Green and Levine (MGL) medication adherence scale, ${ }^{22}$ which was widely used and has been demonstrated to be valid. It consisted of four "yes" or "no" questions. A positive answer was graded 1, whereas a negative answer was graded 0 . Participants were considered adherent to treatment if they scored 0 , and nonadherent if they scored 1 or above.

Patients' knowledge of HTN was assessed using eight "yes" or "no" questions, which based on the literature similar to this topic. ${ }^{18,23}$ It covered the value of HTN, complications, risk factors, lifestyles, etc. An answer with "yes" was scored as 1 point and an answer with "no" was scored as 0 point, with the total score ranging from 0 to 8 . In the current study, the patients with $6-8$ points, $3-5$ points and $0-2$ points were classified as adequate, moderate and poor knowledge, respectively.

\section{Data analysis}

Sociodemographic data, clinical characteristics and knowledge of HTN among the patients were analyzed using descriptive statistics. The univariate analysis of factors for medication adherence was conducted by using Chi-square test. Binary logistic regression analysis was used to analyze independent risk factors for patient's antihypertensive medication adherence. $P<0.05$ was considered to have a significant difference. Statistical analysis was performed using SPSS version 16 (SPSS Inc., Chicago, IL, USA).

\section{Results}

\section{Characteristics of study participants}

Of the initial 564 patients, 124 were excluded for different kinds of reasons, 440 patients were included in the study. A total of $414(94.09 \%)$ patients had ischemic stroke, while $26(5.91 \%)$ had a hemorrhagic stroke. Most of them (91.59\%) were middle and old age with the age above 50 years. A total of $240(54.55 \%)$ of the patients were male, $292(66.36 \%)$
Table I Sociodemographic characteristics of hypertensive stroke patients

\begin{tabular}{lll}
\hline Characteristics & Frequency (n) & Percentage \\
\hline Gender & & \\
$\quad$ Female & 200 & 45.45 \\
$\quad$ Male & 240 & 54.55 \\
Age (years) & & \\
$\quad<50$ & 37 & 8.41 \\
$50-70$ & 213 & 48.41 \\
$\geq 70$ & 190 & 43.18 \\
Occupational status & & \\
Unemployed & 73 & 16.59 \\
Employed & 75 & 17.05 \\
Retired & 292 & 66.36 \\
Health insurance & & \\
Yes & 386 & 87.73 \\
No & 54 & 12.27 \\
Current smoking status & & \\
Yes & 82 & 18.64 \\
No & 358 & 81.36 \\
\hline
\end{tabular}

were retired, $386(87.73 \%)$ had health insurance and 358 $(81.36 \%)$ did not smoke (Table 1). A total of 178 (40.45\%) patients were diagnosed with HTN in the recent 5 years. Patients had several other chronic diseases with $130(29.55 \%)$ had $\geq 3$ other chronic diseases. A total of 324 (73.64\%) took $\leq 1$ anti-HTN medicines every day; 317 (72.05\%) of the patients were diagnosed with stage III HTN; 434 (98.64\%) patients did not experience medicine side effect during the period of taking anti-HTN drugs; $182(41.36 \%)$ patients regularly monitored $\mathrm{BP}$, while 142 (32.27\%) never monitored BP; 347 (78.86\%) and 353 (80.23\%) patients took antiplatelet agents and hypolipidemic agents combined with anti-HTN medication, respectively (Table 2 ).

\section{Knowledge and adherence on HTN}

In the current study, 440 hypertensive stroke patients were assessed for the level of knowledge and adherence, and the risk factors of medication adherence were also analyzed.

Of the 440 patients, 21 (4.77\%) had adequate knowledge, $230(52.27 \%)$ had moderate knowledge, while 189 (42.95\%) had poor knowledge of HTN. Most of the patients (64.77\%) did not know the normal value of BP and $67.27 \%$ patients did not know people with HTN should take medicine in the whole life. Almost half of the patients (49.77\%) knew that eating more salt could increase the chances of developing HTN and $43.18 \%$ of them believed monitoring BP regularly was important. Few of the patients (16.14\%) knew people with HTN might be asymptomatic (Table 3).

Based on the MGL scores, 155 patients (35.23\%) were compliant with their antihypertensive drug treatments, 
Table 2 Clinical characteristics of hypertensive stroke patients

\begin{tabular}{|c|c|c|}
\hline Characteristics & Frequency (n) & Percentage \\
\hline \multicolumn{3}{|c|}{ Duration of HTN (years) } \\
\hline$<5$ & 178 & 40.45 \\
\hline $5-10$ & 81 & $|8.4|$ \\
\hline $10-20$ & 109 & 24.77 \\
\hline$\geq 20$ & 72 & 16.36 \\
\hline \multicolumn{3}{|c|}{ Number of other chronic diseases } \\
\hline$\leq \mathrm{I}$ & 139 & 31.59 \\
\hline 2 & $17 \mid$ & 38.86 \\
\hline$\geq 3$ & 130 & 29.55 \\
\hline \multicolumn{3}{|c|}{ Number of antihypertensive drugs used } \\
\hline$\leq 1$ & 324 & 73.64 \\
\hline 2 & 105 & 23.86 \\
\hline 3 or above & 11 & 2.50 \\
\hline \multicolumn{3}{|l|}{ BP categories } \\
\hline Stage I HTN & 29 & 6.59 \\
\hline Stage II HTN & 94 & 21.36 \\
\hline Stage III HTN & 317 & 72.05 \\
\hline \multicolumn{3}{|c|}{ Experience of side effects } \\
\hline Yes & 6 & 1.36 \\
\hline No & 434 & 98.64 \\
\hline \multicolumn{3}{|c|}{ Regular BP monitoring } \\
\hline Always & 182 & 41.36 \\
\hline Sometimes & 116 & 26.36 \\
\hline No & 142 & 32.27 \\
\hline \multicolumn{3}{|c|}{ Combined with antiplatelet agents } \\
\hline Yes & 347 & 78.86 \\
\hline No & 93 & 21.11 \\
\hline \multicolumn{3}{|c|}{ Combined with hypolipidemic agents } \\
\hline Yes & 353 & 80.23 \\
\hline No & 87 & 19.77 \\
\hline
\end{tabular}

Abbreviations: BP, blood pressure; HTN, hypertension.

Table 3 Knowledge of HTN

\begin{tabular}{|c|c|c|}
\hline Knowledge & $\mathbf{n}$ & $\%$ \\
\hline \multicolumn{3}{|c|}{ Knows the value of HTN } \\
\hline Yes & 155 & 35.23 \\
\hline No & 285 & 64.77 \\
\hline \multicolumn{3}{|c|}{ Knows that people with HTN should take lifelong medical control } \\
\hline Yes & 144 & 32.73 \\
\hline No & 296 & 67.27 \\
\hline \multicolumn{3}{|c|}{ Knows at least two complications of HTN } \\
\hline Yes & 104 & 23.64 \\
\hline No & 336 & 76.36 \\
\hline \multicolumn{3}{|c|}{ Knows importance of regular BP monitoring } \\
\hline Yes & 190 & 43.18 \\
\hline No & 250 & 56.82 \\
\hline \multicolumn{3}{|c|}{ Knows that eating more salt increases the chances of developing HTN } \\
\hline Yes & 219 & 49.77 \\
\hline No & 221 & 50.23 \\
\hline \multicolumn{3}{|c|}{ Knows that being overweight increases the chances of developing HTN } \\
\hline Yes & 150 & 34.09 \\
\hline No & 290 & 65.91 \\
\hline \multicolumn{3}{|c|}{ Knows that people with HTN rarely feel symptoms } \\
\hline Yes & 71 & 16.14 \\
\hline No & 369 & 83.86 \\
\hline \multicolumn{3}{|c|}{ Knows that HTN has relationship with stroke } \\
\hline Yes & 156 & 35.45 \\
\hline No & 284 & 64.55 \\
\hline
\end{tabular}

Abbreviations: BP, blood pressure; HTN, hypertension. while 385 (64.77\%) patients were noncompliant. Univariate analysis of the sociodemographic and clinical factors for medication adherence is provided in Table 4. A total of five factors had $P$-value of $<0.05$, including gender $(P=0.021)$, occupational status $(P=0.033), \mathrm{BP}$ categories $(P=0.044)$, regular BP monitoring $(P<0.001)$ and HTN knowledge $(P<0.001)$.

Table 5 summarizes the result of binary logistic regression analysis. Four factors including gender $(P=0.008), \mathrm{BP}$ categories $(P=0.015)$, regular BP monitoring $(P<0.001)$ and HTN knowledge $(P<0.001)$ were identified to be independently associated with antihypertensive medication adherence. Males $(P=0.008, \mathrm{OR}=2.453,95 \%$ CI $1.258-4.783)$ were less adherent to their drug treatment than females. Comparing to patients with stage I HTN, patients with stage II HTN did not have significant difference about compliance $(P=0.095)$, while patients with stage III HTN were less adherent $(P=0.008, \mathrm{OR}=5.495,95 \% \mathrm{CI} 1.555-19.417)$. Comparing to patients who never monitored $\mathrm{BP}$, patients who always regularly monitored $\mathrm{BP}(P<0.001, \mathrm{OR}=0.001,95 \% \mathrm{CI}$ 0.000-0.006) and the patients who monitored BP sometimes $(P<0.001$, OR $=0.002$, 95\% CI 0.000-0.010) were more adherent. Patients with more knowledge of HTN were more adherent to their drug regimens $(P<0.001, \mathrm{OR}=0.122,95 \%$ CI 0.039-0.380).

\section{Discussion}

Medication adherence is associated with improved BP control and reductions in stroke recidivation for hypertensive stroke patients. $^{24}$ The study revealed that after discharge within about 2 years, only about one-third (35.23\%) of the patients were adhering to the prescribed antihypertensive medications. The medication adherence rate found in this study was much lower than that reported in some developed countries such as the USA (51.3\%), Germany (56.3\%) and the UK (58.4\%). ${ }^{25-27}$ The adherence rate was also lower than that in other developing countries such as Palestine (45.7\%), ${ }^{28}$ Jordan and Lebanon (55.9\%), ${ }^{29}$ and the percentage of adherence is even lower than that in other developed regions in China, such as Shanghai, ${ }^{19}$ as well as Hong Kong. ${ }^{20}$ Cultural and economic factors are crucial factors which could explain different levels of adherence among different populations. ${ }^{30}$ Medication adherence in the northwestern regions of China with low cultural level and underdeveloped economy should be paid more attention by Chinese health care professionals and health care policy makers. The study reminds Chinese government to provide additional health care for this region.

A few of studies have also evaluated the factors related to antihypertensive medication adherence. ${ }^{31}$ Age, gender, the 
Table 4 Factors associated with optimal medication adherence $(\mathrm{N}=440)$

\begin{tabular}{|c|c|c|c|}
\hline \multirow[t]{2}{*}{ Factors } & \multicolumn{2}{|l|}{ n (\%) } & \multirow[t]{2}{*}{$P$-value } \\
\hline & Good adherence & Poor adherence & \\
\hline \multicolumn{3}{|l|}{ Gender } & 0.021 \\
\hline Female & $82(41.00)$ & $118(59.00)$ & \\
\hline Male & $73(30.42)$ & $167(69.58)$ & \\
\hline \multicolumn{3}{|l|}{ Age (years) } & 0.920 \\
\hline$<50$ & $13(35.14)$ & $24(64.86)$ & \\
\hline $50-70$ & $77(36.15)$ & $136(63.85)$ & \\
\hline$\geq 70$ & $65(34.2 I)$ & $125(65.79)$ & \\
\hline \multicolumn{3}{|c|}{ Occupational status } & 0.033 \\
\hline Unemployed & $16(21.92)$ & 57 (78.08) & \\
\hline Employed & $28(37.33)$ & $47(62.67)$ & \\
\hline Retired & $111(38.01)$ & $181(61.99)$ & \\
\hline \multicolumn{3}{|l|}{ Health insurance } & 0.221 \\
\hline Yes & $140(36.27)$ & $246(63.73)$ & \\
\hline No & $15(27.78)$ & $39(72.22)$ & \\
\hline \multicolumn{3}{|c|}{ Current smoking status } & 0.977 \\
\hline Yes & $29(35.37)$ & $53(64.63)$ & \\
\hline No & $126(35.20)$ & $232(64.80)$ & \\
\hline \multicolumn{3}{|c|}{ Duration of HTN (years) } & 0.382 \\
\hline$<5$ & $56(31.46)$ & $122(68.54)$ & \\
\hline $5-10$ & $27(33.33)$ & $54(66.67)$ & \\
\hline $10-20$ & $42(38.53)$ & $67(61.47)$ & \\
\hline$\geq 20$ & $30(4 \mid .67)$ & $42(58.33)$ & \\
\hline \multicolumn{3}{|c|}{ Number of other chronic diseases } & 0.149 \\
\hline$\leq 1$ & $58(4 \mid .73)$ & 81 (58.27) & \\
\hline 2 & $56(32.75)$ & $115(67.25)$ & \\
\hline$\geq 3$ & $41(31.54)$ & $89(68.46)$ & \\
\hline \multicolumn{3}{|c|}{ Number of antihypertensive drugs used } & 0.705 \\
\hline$\leq 1$ & $115(35.49)$ & $209(65.5 \mathrm{I})$ & \\
\hline 2 & $35(33.33)$ & $70(66.67)$ & \\
\hline 3 or above & $5(45.45)$ & $6(54.55)$ & \\
\hline \multicolumn{3}{|l|}{ BP categories } & 0.044 \\
\hline Stage I HTN & $13(44.83)$ & $16(55.17)$ & \\
\hline Stage II HTN & $42(44.21)$ & $53(55.79)$ & \\
\hline Stage III HTN & $100(31.65)$ & $216(68.35)$ & \\
\hline \multicolumn{3}{|c|}{ Experience of side effects } & 0.338 \\
\hline Yes & I (16.67) & $5(83.33)$ & \\
\hline No & $154(35.48)$ & $280(64.52)$ & \\
\hline \multicolumn{3}{|c|}{ Regular BP monitoring } & $<0.001$ \\
\hline Always & $112(62.57)$ & $67(37.43)$ & \\
\hline Sometimes & $41(34.75)$ & $77(65.25)$ & \\
\hline No & $2(1.40)$ & $141(98.60)$ & \\
\hline \multicolumn{3}{|c|}{ Combined with antiplatelet agents } & 0.706 \\
\hline Yes & $130(35.62)$ & $235(64.38)$ & \\
\hline No & $25(33.33)$ & $50(66.67)$ & \\
\hline \multicolumn{3}{|c|}{ Combined with hypolipidemic agents } & 0.622 \\
\hline Yes & $126(34.7 \mid)$ & 237 (65.29) & \\
\hline No & $29(37.66)$ & $48(62.34)$ & \\
\hline \multicolumn{3}{|l|}{ HTN knowledge } & $<0.00$ I \\
\hline Poor & $4 \mathrm{I}(21.69)$ & I $48(78.3 \mid)$ & \\
\hline Moderate & $99(43.04)$ & |3| (56.96) & \\
\hline Good & $15(7 \mid .43)$ & $6(28.57)$ & \\
\hline
\end{tabular}

Abbreviations: BP, blood pressure; HTN, hypertension.

number of prescribed antihypertensives, etc were found to be associated with drug adherence. The association between gender and medication adherence is complicated, and the
Table 5 Binary logistic regression analysis of factors associated with adherence in hypertensive stroke patients

\begin{tabular}{|c|c|c|}
\hline Variables & OR $(95 \% \mathrm{Cl})$ & $P$-value \\
\hline \multicolumn{3}{|l|}{ Gender } \\
\hline Female & 1.000 & - \\
\hline Male & $2.453(1.258-4.783)$ & 0.008 \\
\hline \multicolumn{3}{|l|}{ BP categories } \\
\hline Stage I HTN & 1.000 & 0.015 \\
\hline Stage II HTN & $3.075(0.82|-| 1.520)$ & 0.095 \\
\hline Stage III HTN & $5.495(1.555-19.417)$ & 0.008 \\
\hline \multicolumn{3}{|c|}{ Regular BP measurement } \\
\hline No & 1.000 & $<0.001$ \\
\hline Sometimes & $0.002(0.000-0.010)$ & $<0.001$ \\
\hline Always & $0.001(0.000-0.006)$ & $<0.001$ \\
\hline \multicolumn{3}{|l|}{ HTN knowledge } \\
\hline Poor & 1.000 & $<0.001$ \\
\hline Moderate & $0.035(0.017-0.075)$ & $<0.001$ \\
\hline Good & $0.122(0.039-0.380)$ & $<0.001$ \\
\hline
\end{tabular}

Abbreviations: BP, blood pressure; HTN, hypertension.

conclusion is mixed in literatures. Females were found to be more adherent in this study. This finding was consistent with some of studies that showed females were associated with better adherence to antihypertensive agents than males, ${ }^{32,33}$ while some other studies showed the opposite. ${ }^{34}$ Another study conducted by Holt et al ${ }^{135}$ reported that the prevalence of low medication adherence scores did not differ according to gender ( $15.0 \%$ in women and $13.1 \%$ in men $P=0.208$ ). The possible reason why females were more adherent is that females are often more careful and pay more attention to the treatment of HTN. Furthermore, males usually afford more heavy pressure from job and are busier than females so they often forget to take medicines, which may also lead to poor drug adherence.

In this study, classification of HTN was also found to affect medication adherence. Our study found that patients diagnosed with stage III HTN were less adherent than patients with stage I HTN or stage II HTN. Few studies have reported that BP categories are associated with medication compliance. This finding is similar to the result of a study conducted by Alhaddad et al, ${ }^{29}$ which reported that patients diagnosed with stage II HTN were less adherent than patients with stage I HTN and prehypertension. However, they did not include stage III HTN in the classification of BP in their study. The possible reason is patients undergoing stage III HTN usually experience longer period of time after diagnosed with HTN and some of them are afraid of drug addiction or drug side effects.

The study pointed out that patients' anti-HTN medication adherence was associated with patients' knowledge of HTN. Poor knowledge of HTN negatively affected medication adherence. In the current study, about half (42.95\%) of the patients showed poor knowledge of HTN such as the definition, risk factors, treatment, complications, the relation 
with stroke, etc. Previous published studies confirmed that the poor knowledge of HTN among patients and lack of appropriate education influenced the adherence of HTN. ${ }^{36}$ High knowledge of HTN were positively associated with high adherence. ${ }^{37,38}$ A study conducted by Teshome et al ${ }^{39}$ reported that hypertensive patients who had good knowledge about HTN and its treatment were nine times as likely to adhere to their medication therapy as compared to patients who had poor knowledge. So it is important to provide supports to patients in understanding the knowledge about their disease and its treatment. Clinical pharmacists' face-to-face education for patients during hospitalization should be taken to increase patient's awareness about the disease, treatment, risk of complications and the importance of monitoring the disease, and thus improves medication adherence and leads to better BP control. It is equally important for clinical pharmacists to pay a regular return visit to discharged patients. Moreover, improved adherence behavior would be achieved in multiple visits rather than a single visit or with a short-term intervention. However, it may require health policy changes to permit reimbursement for clinical pharmacists' delivery of intervention activities. ${ }^{40}$

More than half of the patients in this study monitored BP at home. The traditional home-based BP monitor was used to monitor BP. Our study showed that whether regularly monitored BP or monitored BP sometimes it could increase the medication adherence compared to patients who never monitored BP. It demonstrated that it had significant association between drug adherence and home BP monitoring. The possible reason was the patients who regularly monitored BP paid more attention to their health than the one who never monitored BP and they can know their BP levels in time. So it is important to carry out a regular BP measurement to improve HTN medication compliance. The American Heart Association recommends home BP monitoring for all people with HTN. In developed countries, many new BP devices, apps and remote monitoring systems are available for patients to monitor their BP, which may improve medication adherence and HTN control. ${ }^{41}$

Patient-tailored interventions are required to improve medication adherence to therapeutic drug regimens. ${ }^{42}$ Several interventions to improve patients' medication adherence have been developed such as reminder packaging, mobile health (mHealth) services and electronic medication monitoring devices. ${ }^{4,43,44}$ Although these strategies have been shown to improve adherence to medications, the majority of them are associated with high costs and health professional resources, which are difficult to be available in developing countries, ${ }^{38}$ such as China. China's health care system lacks financial and professional human resources, especially in our undeveloped region, and most of the adherence-increasing interventions are not feasible.

Compared to the expensive and unavailable strategies, pharmacist-led services are more feasible in China. Pharmacists play a vital role in the health care system and can substantially improve the value of pharmacotherapy. ${ }^{45}$ A study conducted in the USA found that patient education services by pharmacists could improve adherence to chronic disease medications. ${ }^{46}$ Another study reported by Sanii et al found that pharmacist counseling, necessary education about prescribed medications at the time of discharge and regular follow-up improved patient's medication adherence. ${ }^{47}$ Clinical pharmacists should spend more time to adequately and patiently counsel about treatment in hypertensive patients. Hospitalization and subsequent discharge often involve discontinuity of care, so it is equally important for clinical pharmacists to pay a regular visit to discharged patients.

Short messaging service (SMS) reminders are also a content of pharmaceutical care; daily SMS reminders by pharmacists could effectively improve patients' adherence to medication intake and it is financially affordable also in low resource setting. ${ }^{38}$ In a recent meta-analysis of more than 3,000 patients, mobile phone text reminders increased medication adherence from $50 \%$ to $68 \%{ }^{48}$ Telephone-based motivational interviewing may also be a promising intervention to improve adherence. . $^{49,50}$

The mHealth technology has increasingly been investigated in delivering the health interventions in the developed countries. It may improve noncommunicable disease outcomes. ${ }^{51}$ Currently, more than $100,000 \mathrm{mHealth}$ apps are available, many of which are marketed to the consumer to address HTN control or medication adherence. ${ }^{41}$ However, mHealth service is in the preliminary stage of development in China. Some provinces are preparing to develop an mHealthBased Health Management Platform. ${ }^{52}$ It is not currently available in the northwestern region of China, however, it will be the future development direction.

There are some limitations. First, the study was carried out by telephone survey, so some of the patients could not be contacted, leading to missing data. Second, although the patients of the hospital are from various regions of the northwest, the majority of the patients are the local resident. It cannot present the overall level of the patients in the whole northwestern China coupled with the small sample size. Third, lifestyle-related factors with medicine adherence were seldom examined in this study. Finally, some data 
were collected by self-reported questionnaires, which may introduce recall bias. Larger studies in wider areas and more focus on lifestyle or other risk factors should be carried out in future studies.

\section{Conclusion}

In our study, almost two-thirds of the participants were nonadherent to antihypertensive medication after discharge within 2 years. Gender, HTN categories, BP monitoring and HTN knowledge were found to be the main factors affecting adherence. Almost half of the patients had poor knowledge of HTN. Medication adherence of hypertensive stroke patients should be given more attention by health care professionals and health care policy makers in northwestern China. Clinical pharmacists should play an important role in improving patients' medication adherence.

\section{Disclosure}

The authors report no conflicts of interest in this work.

\section{References}

1. Grassi G, Quarti F, Mancia G. Hypertension, antihypertensive treatment and stroke prevention. Neurol Sci. 2005;26(S1):s22-s23.

2. Aronow WS. Hypertension-related stroke prevention in the elderly. Curr Hypertens Rep. 2013;15(6):582-589.

3. Gaciong Z, Siński M, Lewandowski J. Blood pressure control and primary prevention of stroke: summary of the recent clinical trial data and meta-analyses. Curr Hypertens Rep. 2013;15(6):559-574.

4. Piette JD, Datwani H, Gaudioso S, et al. Hypertension management using mobile technology and home blood pressure monitoring: results of a randomized trial in two low/middle-income countries. Telemed $E$ Health. 2012;18(8):613-620.

5. Gleason-Comstock J, Streater A, Goodman A, et al. Willingness to pay and willingness to accept in a patient-centered blood pressure control study. BMC Health Serv Res. 2017;17(1):538.

6. Liao Y, Gilmour S, Shibuya K. Health insurance coverage and hypertension control in China: results from the China Health and Nutrition Survey. PLoS One. 2016;11(3):e0152091.

7. Li Y, Wang JL, Zhang XC, et al. Effectiveness of adherence to standardized hypertension management by primary health care workers in China: a cross-sectional survey 3 years after the healthcare reform. Biomed Environ Sci. 2016;29(12):915-921.

8. Vrijens B, De Geest S, Hughes DA, et al; ABC Project Team. A new taxonomy for describing and defining adherence to medications. $\mathrm{Br} \mathrm{J}$ Clin Pharmacol. 2012;73(5):691-705.

9. Ahmad N, Hassan Y, Tangiisuran B, et al. Guidelines adherence and hypertension control at a tertiary hospital in Malaysia. J Eval Clin Pract. 2013;19(5):798-804.

10. Rowan CG, Turner JR, Shah A, Spaeder JA. Antihypertensive treatment and blood pressure control relative to hypertension treatment guidelines. Pharmacoepidem Drug Safety. 2014;23(12):1294-1302.

11. Souza AC, Borges JW, Moreira TM. Quality of life and treatment adherence in hypertensive patients: systematic review with meta-analysis. Rev Saude Publ. 2016;50:71.

12. Burnier M. Drug adherence in hypertension. Pharmacol Res. 2017; 125(pt B):142-149.

13. Abegaz TM, Shehab A, Gebreyohannes EA, Bhagavathula AS, Elnour AA. Nonadherence to antihypertensive drugs. Medicine. 2017; 96(4):e5641.
14. van der Laan DM, Elders PJM, Boons CCLM, Beckeringh JJ, Nijpels G, Hugtenburg JG. Factors associated with antihypertensive medication non-adherence: a systematic review. J Hum Hypertens. 2017;31(11): 687-694.

15. AlGhurair SA, Hughes CA, Simpson SH, Guirguis LM. A systematic review of patient self-reported barriers of adherence to antihypertensive medications using the World Health Organization Multidimensional Adherence Model. J Clin Hypertens. 2012;14(12):877-886.

16. Brown MT, Bussell JK. Medication adherence: WHO cares? Mayo Clin Proc. 2011;86(4):304-314.

17. Nielsen J, Shrestha AD, Neupane D, Kallestrup P. Non-adherence to anti-hypertensive medication in low- and middle-income countries: a systematic review and meta-analysis of 92443 subjects. J Hum Hypertens. 2017;31(1):14-21.

18. Akoko BM, Fon PN, Ngu RC, Ngu KB. Knowledge of hypertension and compliance with therapy among hypertensive patients in the Bamenda Health District of Cameroon: a cross-sectional study. Cardiol Ther. 2016;6(1):53-67.

19. Yue Z, Bin W, Weilin Q, Aifang Y. Effect of medication adherence on blood pressure control and risk factors for antihypertensive medication adherence. J Eval Clin Pract. 2015;21(1):166-172.

20. Kang CD, Tsang PPM, Li WTL, et al. Determinants of medication adherence and blood pressure control among hypertensive patients in Hong Kong: a cross-sectional study. Int J Cardiol. 2015;182:250-257.

21. Campos CL, Pierin AMG, Pinho NA. Hypertension in patients admitted to clinical units at university hospital: post-discharge evaluation rated by telephone. Einstein (São Paulo). 2017;15(1):45-49.

22. DE M, LW G, DM L. Concurrent and predictive validity of a selfreported measure of medication adherence. Med Care. 1986;24:67-74.

23. Zhang XP, Zhu MM, Dib HH, et al. Knowledge, awareness, behavior $(\mathrm{KAB})$ and control of hypertension among urban elderly in Western China. Int J Cardiol. 2009;137(1):9-15.

24. Mugwano I, Kaddumukasa M, Mugenyi L, et al. Poor drug adherence and lack of awareness of hypertension among hypertensive stroke patients in Kampala, Uganda: a cross sectional study. BMC Res Notes. 2016; $9(1): 3$.

25. Schulz M, Krueger K, Schuessel K, et al. Medication adherence and persistence according to different antihypertensive drug classes: a retrospective cohort study of 255,500 patients. Int J Cardiol. 2016;220: 668-676.

26. Gupta P, Patel P, Strauch B, et al. Risk factors for non-adherence to antihypertensive treatment. Hypertension. 2017;69(6):1113-1120.

27. Lauffenburger JC, Landon JE, Fischer MA. Effect of combination therapy on adherence among US patients initiating therapy for hypertension: a Cohort Study. J Gen Intern Med. 2017;32(6): 619-625.

28. Fontil V, Bibbins-Domingo K, Kazi DS, et al. Simulating strategies for improving control of hypertension among patients with usual source of care in the United States: the blood pressure control model. J Gen Intern Med. 2015;30(8):1147-1155.

29. Alhaddad IA, Hamoui O, Hammoudeh A, Mallat S. Treatment adherence and quality of life in patients on antihypertensive medications in a Middle Eastern population: adherence. Vasc Health Risk Manag. 2016; 12:407-413.

30. Lee GK, Wang HH, Liu KQ, Cheung Y, Morisky DE, Wong MC. Determinants of medication adherence to antihypertensive medications among a Chinese population using Morisky Medication Adherence Scale. PLoS One. 2013;8(4):e62775.

31. Mejia CR, Failoc-Rojas VE, So E, et al. Characteristics and factors associated with antihypertensive medication use in patients attending Peruvian health facilities. Cureus. 2017;9(2):e1011.

32. Yassine M, Al-Hajje A, Awada S, et al. Evaluation of medication adherence in Lebanese hypertensive patients. J Epidemiol Glob Health. 2016;6(3):157-167.

33. Wong MCS, Jiang JY, Griffiths SM. Factors associated with antihypertensive drug compliance in 83884 Chinese patients: a cohort study. J Epidemiol Commun Health. 2010;64(10):895-901. 
34. Jankowska-Polanska B, Chudiak A, Uchmanowicz I, Dudek K, Mazur G. Selected factors affecting adherence in the pharmacological treatment of arterial hypertension. Patient Prefer Adher. 2017;11: 363-371.

35. Holt E, Joyce C, Dornelles A, et al. Sex differences in barriers to antihypertensive medication adherence: findings from the cohort study of medication adherence among older adults. J Am Geriatr Soc. 2013; 61(4):558-564.

36. Malik A, Yoshida Y, Erkin T, Salim D, Hamajima N. Hypertensionrelated knowledge, practice and drug adherence among inpatients of a hospital in Samarkand, Uzbekistan. Nagoya J Med Sci. 2014;76(3-4): 255-263.

37. Bandi P, Goldmann E, Parikh NS, Farsi P, Boden-Albala B. Age-related differences in antihypertensive medication adherence in Hispanics: a cross-sectional community-based survey in New York City, 2011-2012. Prev Chronic Dis. 2017;14:E57.

38. Haramiova Z, Stasko M, Hulin M, Tesar T, Kuzelova M, Morisky DM. The effectiveness of daily SMS reminders in pharmaceutical care of older adults on improving patients' adherence to antihypertensive medication (SPPA): study protocol for a randomized controlled trial. Trials. 2017;18(1):334.

39. Teshome DF, Bantie Bekele K, Habitu Y, Addis Gelagay A. Medication adherence and its associated factors among hypertensive patients attending the Debre Tabor General Hospital, northwest Ethiopia. Integr Blood Press Control. 2017;10:1-7.

40. Conn VS, Ruppar TM, Chase J-AD, Enriquez M, Cooper PS. Interventions to improve medication adherence in hypertensive patients: systematic review and meta-analysis. Curr Hypertens Rep. 2015;17(12):94.

41. Goldberg EM, Levy PD. New approaches to evaluating and monitoring blood pressure. Curr Hypertens Rep. 2016;18(6):49.

42. Vrijens B, Antoniou S, Burnier M, de la Sierra A, Volpe M. Current situation of medication adherence in hypertension. Front Pharmacol. 2017;8:100
43. Gupta P, Patel P, Horne R, Buchanan H, Williams B, Tomaszewski M. How to screen for non-adherence to antihypertensive therapy. Curr Hypertens Rep. 2016;18(12):89.

44. Mahtani KR, Heneghan CJ, Glasziou PP, Perera R, Mahtani KR. Reminder packaging for improving adherence to self-administered long-term medications. Cochrane Database Syst Rev. 2011;(9): CD005025.

45. Allemann SS, van Mil JWF, Botermann L, Berger K, Griese N, Hersberger KE. Pharmaceutical care: the PCNE definition 2013. Int J Clin Pharm. 2014;36(3):544-555.

46. Oung AB, Kosirog E, Chavez B, Brunner J, Saseen JJ. Evaluation of medication adherence in chronic disease at a federally qualified health center. Ther Adv Chronic Dis. 2017;8(8-9):113-120.

47. Sanii Y, Torkamandi H, Gholami K, Hadavand N, Javadi M. Role of pharmacist counseling in pharmacotherapy quality improvement. J Res Pharm Pract. 2016;5(2):132-137.

48. Thakkar J, Kurup R, Laba TL, et al. Mobile telephone text messaging for medication adherence in chronic disease a meta-analysis. JAMA Intern Med. 2016;176(3):340-349.

49. Palacio A, Garay D, Langer B, Taylor J, Wood BA, Tamariz L. Motivational interviewing improves medication adherence: a systematic review and meta-analysis. J Gen Intern Med. 2016;31(8):929-940.

50. Teeter BS, Kavookjian J. Telephone-based motivational interviewing for medication adherence: a systematic review. Transl Behav Med. 2014;4(4):372-381.

51. Rehman H, Kamal AK, Morris PB, Sayani S, Merchant AT, Virani SS. Mobile health (mHealth) technology for the management of hypertension and hyperlipidemia: slow start but loads of potential. Curr Atheroscler Rep. 2017;19(3):12.

52. Zhang HH, Zhang H, Wang XN, Yang ZS, Zhao YH. Analysis of requirements for developing an mHealth-based health management platform. JMIR Mhealth Uhealth. 2017;5(8):e117.
Patient Preference and Adherence

\section{Publish your work in this journal}

Patient Preference and Adherence is an international, peer-reviewed, open access journal that focuses on the growing importance of patient preference and adherence throughout the therapeutic continuum. Patient satisfaction, acceptability, quality of life, compliance, persistence and their role in developing new therapeutic modalities and compounds to optimize

\section{Dovepress}

clinical outcomes for existing disease states are major areas of interest for the journal. This journal has been accepted for indexing on PubMed Central. The manuscript management system is completely online and includes a very quick and fair peer-review system, which is all easy to use. Visit http://www. dovepress.com/testimonials.php to read real quotes from published authors. 